\title{
Serial imaging and outcome prediction
}

\author{
Ami E. Iskandrian, MD, MACC, MASNC, ${ }^{a}$ Christopher P. Roth, MD, and \\ Fadi G. Hage, MD, FACC, FASH ${ }^{\mathrm{a}, \mathrm{b}}$ \\ a Division of Cardiovascular Disease, Department of Medicine, University of Alabama at \\ Birmingham, Birmingham, AL \\ ${ }^{b}$ Section of Cardiology, Birmingham Veterans Affairs Medical Center, Birmingham, AL
}

Received Sep 29, 2015; accepted Oct 9, 2015

doi: $10.1007 / \mathrm{s} 12350-015-0312-3$

When one considers the many types of cardiovascular events and the many causes of death in patients with suspected or known to have coronary artery disease (Tables 1,2), one must marvel at how well myocardial perfusion imaging (MPI) with single-photon emission computed tomography (SPECT) and positron emission tomography (PET) have performed in predicting major adverse cardiac events (MACE). ${ }^{1}$ Predicting death and its timing is not easy and likely could not be done perfectly solely on the basis of the myocardial perfusion pattern, myocardial blood flow (MBF), left ventricular (LV) ejection fraction (EF), innervation, or even all of these combined. ${ }^{1,2}$ For that reason, many studies have incorporated additional pieces of information such as demographic, socioeconomic, psychosocial, environmental, biochemical, anatomic, and genetic factors to refine the process.

There are fewer data on the prediction of the individual endpoints of MACE and even less on the mechanisms of the associations or causations. In some ways, mixing different endpoints into combined outcomes have hindered our ability to focus on the mechanistic aspects. For example, the implications and mechanisms of cardiac death are likely entirely different from those of non-fatal myocardial infarction, coronary revascularization, and quality of life measures.

Another observation in outcome data is the paucity of data on serial imaging and the mechanisms involved in worsening or improvement and the relation of such to specific endpoints (Tables $3,4,5,6,7,8,9,10) .{ }^{3}$ In this

Reprint requests: Ami E. Iskandrian MD, MACC, MASNC, Division of Cardiovascular Disease, Department of Medicine, University of Alabama at Birmingham, 318 LHRB, 1900 University BLVD, Birmingham, AL 35294, USA; aiskand@uab.edu

J Nucl Cardiol 2016;23:117-21.

$1071-3581 / \$ 34.00$

Copyright (c) 2015 American Society of Nuclear Cardiology. issue of the Journal, there is one report on MPI serial imaging. ${ }^{4}$

Comparison of two sets of images performed at two different time intervals is inherently complicated by the fact that the changes in myocardial perfusion or MBF are not only the result of the specific intervention (for example statin therapy) but are also influenced by biological variability and by the precision and accuracy of the method used. ${ }^{3,5-20}$ Visual methods might be accurate but not reproducible, and automated methods might be reproducible but not precise. ${ }^{20,21}$ A common practice is to compare patient data to a normal database, but alternative methods are available that compare the two sets of images to each other directly rather than comparing each to a normal database. Such an approach may improve the detection of smaller interval changes (improvement or worsening) since the intra-patient variation is expected to be smaller than the inter-patient variation. ${ }^{5-10}$

Given the fact that we have had more than four decades of experience in nuclear cardiac imaging (more than any other imaging modality except invasive coronary angiography!), that ischemic heart disease is a dynamic process, that the course of the disease could be altered by therapy, and that patient survival has improved over the decades, one would expect many more studies based on serial changes on imaging. It may very well be that the data are there but not reported because the analysis is not easy! It is hard to believe that repeat imaging was not performed in studies that report outcome data of more than 5 years of follow-up even in the current era of appropriate use criteria which have slowed the pace of routine serial imaging.

When considering serial images, one needs to consider the initial results (first study), the final results (second study), and the change between the first and the second studies (expressed either as absolute or relative) (Table 9). ${ }^{3}$ Consider for example 2 patients: in patient $\mathrm{A}$ the defect size (or MPF) decreased from 50\% on initial 
Table 1. Common types of events used in outcome studies

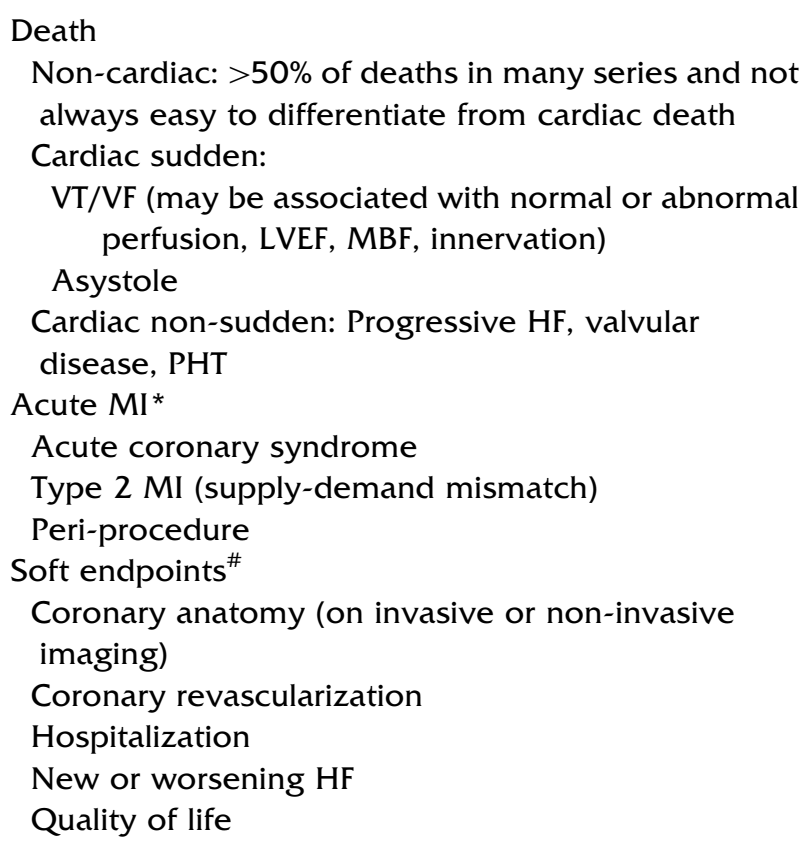

$M B F$, myocardial blood flow; $L V E F$, left ventricular ejection fraction; $M I$, myocardial infarction, $H F$, heart failure, $M R$, mitral regurgitation, $P H T$, pulmonary hypertension, $V T$, ventricular tachycardia; $V F$, ventricular fibrillation

* Size of MI is variable, e.g., a large MI that involves the entire anterior wall is likely different from a small rise in highsensitivity troponin that is not associated with a change in other markers

\# With soft endpoints, there is regional and subjective variability in rate of events, and the issue of appropriateness of the event should be considered

Table 2. Outcome assessment and compounding factors

Time between index test and outcome

Inc biases: examples:

High-risk patients are triaged for early coronary revascularization

High-risk patients with inoperable anatomy are treated medically

Patients with multiple co-morbidities are treated medically

Patients that are revascularized early after imaging (typically within 90 days) are usually excluded from analysis

Variation in intensity of medical therapy

Variation in completeness of revascularization

Serial studies are done but only the initial studies are analyzed
Table 3. Assessment of serial changes in myocardial perfusion and LVEF

(a) Extent of stress-induced or rest perfusion defect or both

(b) Severity of stress-induced or rest perfusion defect or both

(c) Extent and severity of stress-induced or rest perfusion defect or both

(d) Left ventricular ejection fraction, volumes, synchrony, innervation, transient ischemic dilation, and post-stress stunning

The change can signify improvement or worsening and can be expressed globally or regionally

Table 4. Some of the factors to be considered in the comparison of serial studies

\author{
Technical \\ Image quality \\ Imaging sequence \\ Tracer \\ Tracer used \\ Tracer dose \\ Time of imaging in relation to tracer injection \\ Cameras used \\ Attenuation \\ Use of attenuation/scatter correction \\ Left arm position during imaging \\ Breast position during imaging \\ Stress modality \\ Exercise vs pharmacologic \\ Exercise work load and double product \\ Type of pharmacologic stress \\ Medications \\ Intervening events \\ $\mathrm{MI}$ \\ Coronary revascularization
}

study to $30 \%$ on follow-up study (a $20 \%$ absolute or $40 \%$ relative decrease). In patient $\mathrm{B}$, the defect size increases from $10 \%$ on initial study to $20 \%$ on follow-up study (a 10\% absolute and $100 \%$ relative increase). While patient A had improvement and patient B worsening, the residual abnormality is still larger in patient $\mathrm{A}$ than B (30\% vs 20\%). In addition, interpreting the change may even be more complex than this in specific patients. For example, it is possible that perfusion pattern (or MBF) improves in one vascular territory but worsens in another territory with a net effect of no 
Table 5. Methods of assessment of serial images

1. Side-by-side: Automated with visual overread*

2. Visual: It has a definite role as all automated programs have a threshold for defining what is normal/abnormal or reversible/fixed but not the eye of an expert reader!

3. Number of abnormal segments (17-segment model) based on visual reading. This method lacks information on severity changes

4. SSS, SDS, and SRS based on visual reading (17segment model): inter-reader variability. The scores reflect extent and severity but lack information on location. Hence, directionally opposite changes in extent and severity might not be reflected reliably in these scores

5. SSS, SDS, and SRS based on automated reading (17-segment model): More reproducible than visual but lack information on location (see number 4 above)

6. Polar maps: These are derived using automated programs. Different softwares provide defect size and severity separately or combined into one score. Each method has advantages and limitations. Perfusion is compared to a normal database. In addition to global information (similar to SSS/SDS/ SRS), polar maps provide information on location. Require reader supervision

7. Automated paired analysis whereby the 2 studies are compared to each other rather than to a normal database. Very attractive as the intra-patient differences might be smaller than inter-patient differences and hence smaller changes are detected

SSS, summed stress score; SRS, summed rest score; SDS, summed difference score

* Preferred method

\section{Table 6. Changes in $\mathrm{MBF}$}

1. Changes in resting global MBF

2. Changes in resting regional MBF

3. Changes in global peak (hyperemic) MBF

4. Changes in regional peak (hyperemic) MBF

5. Changes in global CFR

6. Changes in regional CFR

$C F R$, coronary flow reserve ratio; $M B F$, myocardial blood flow

change in the total abnormality. Although this is an extreme example, opposing changes in perfusion pattern in different vascular territories are not uncommon and it
Table 7. Reasons for worsening of reversible perfusion defect in serial studies

\section{Artifact}

2. A decrease in peak flow in culprit vessel in study 2 compared to study 1 , assuming that peak flow in control zone is unchanged

3. An improvement in peak flow in normal (control) zone in study 2 compared to study 1 , assuming that the peak flow in culprit zone is unchanged

Table 8. Reasons for improvement in reversible perfusion defect in serial studies

1. Artifact

2. An improvement in peak flow in culprit zone in study 2 compared to study 1 , assuming that peak flow in control zone is unchanged

3. A decrease in peak flow in normal (control) zone in study 2 compared to study 1 , assuming that peak flow in culprit zone is unchanged

Table 9. Expressing the change in perfusion in relative and absolute terms both globally and regionally

\begin{tabular}{|c|c|c|c|c|}
\hline \multicolumn{5}{|l|}{$\begin{array}{l}\text { Global } \\
\text { Relative } \\
\text { Absolute }\end{array}$} \\
\hline SSS & LAD & RCA & LCX & Global \\
\hline Study 1 & 12 & 6 & 0 & 18 \\
\hline Study 2 & 2 & 6 & 0 & 8 \\
\hline $\begin{array}{c}\text { Improvement/ } \\
\text { (worsening)- } \\
\text { relative }(\%)\end{array}$ & 83 & 0 & 0 & 56 \\
\hline $\begin{array}{l}\text { Improvement/ } \\
\text { (worsening)- } \\
\text { absolute }\end{array}$ & 10 & 0 & 0 & 10 \\
\hline
\end{tabular}

The table shows an example of improvement based on SSS, but the same concept can be used for other parameters listed in Table 3

$L A D$, left anterior descending artery; $L C X$, left circumflex artery; $R C A$, right coronary artery; SSS, summed stress score

is hard to account for these changes in outcome studies (Table 5). Finally, the perfusion changes seen on the serial studies may reflect MBF changes in culprit zone as well as the normal (control) zone (Figure 1; Tables 7, 8). Here may lay the problem of how best to model complex changes in outcome prediction. 
Table 10. Practical considerations for serial testing

1. It is easier to compare 2 studies when both are normal and of good quality

2. It is easier to compare 2 studies when one is normal and the other is abnormal

3. It is more difficult to compare 2 studies when any one of the 4 image sets ( 2 stress and 2 rest) is of poor quality

4. It is more difficult to compare 2 studies when there are mixed fixed and reversible defects on both studies

5. Improvement in resting perfusion may be observed, which suggests that not all fixed defects are due to scar

6. The report should detail the change in perfusion in a meaningful way. This is often not easy, within the constraints of templates, used for reporting a single study. Creativity is important to personalized reporting. A phone call to the referring physician is often useful when the changes are complex

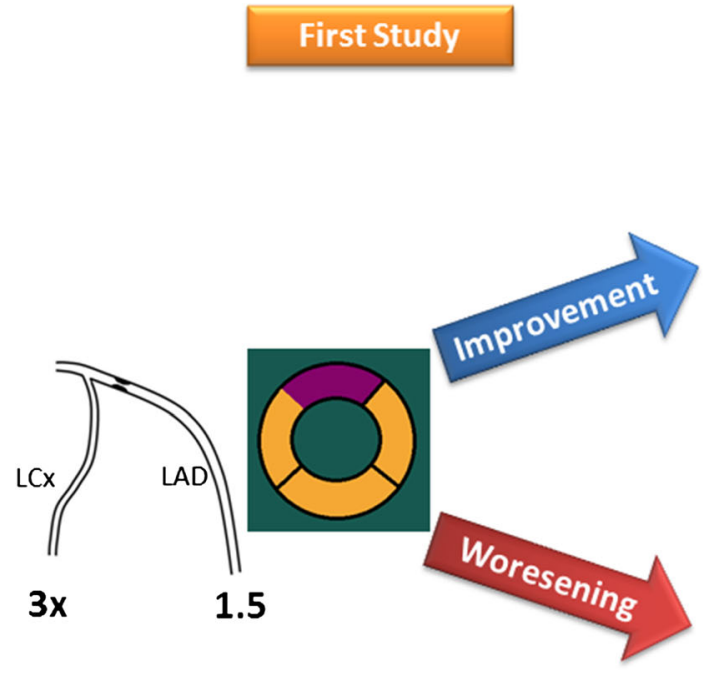

Hopefully, our message may in a small way pave the way for more reports. Specifically, there is a need to define the best methods to evaluate changes observed on serial imaging and how to use the data in patient management and predicting different outcome endpoints. Many of the issues summarized are not limited to MPI and may be equally pertinent to other imaging modalities. uptake, Purple to decrease in tracer uptake.

\section{Second Study}

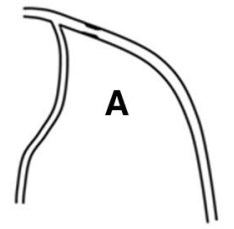

$3 x$

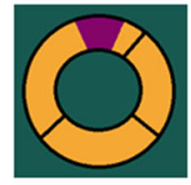

$2 x$

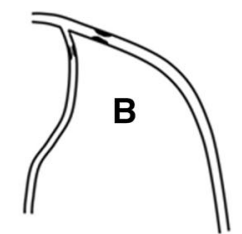

$2.5 x$

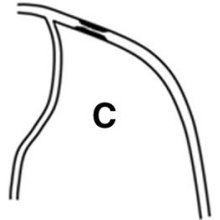

$1.3 x$

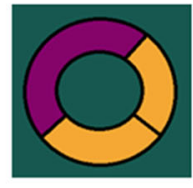

$4 x$

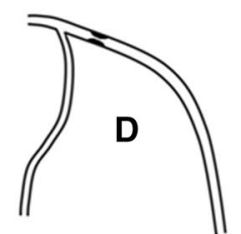

$1.5 x$
Figure 1. Change in myocardial perfusion pattern on serial studies. A perfusion defect (purple) is shown on the first study corresponding to stenotic lesion in the LAD. The peak blood flow as a factor of resting blood flow $(x)$ is shown below each coronary artery. On the second study, the potential changes in peak blood flow corresponding to improvement or worsening on MPI are shown. In scenarios A \& B, there is improvement in the perfusion defect, while in C \& D there is worsening. Note that the peak blood flow in the LAD improves in scenario A and worsens in C, while it does not change in B \& D. The changes in the perfusion defect in B \& D are related to the change in peak blood flow in the LCx 'normal' region. The illustration is a simplistic depiction of the changes which does not take into account the non-linear uptake of tracers by the myocardium. $L A D$ left anterior descending artery; $L C x$ left circumflex artery. Yellow corresponds to normal tracer

\section{References}

1. Shaw LJ, Hage FG, Berman DS, Hachamovitch R, Iskandrian A. Prognosis in the era of comparative effectiveness research: Where is nuclear cardiology now and where should it be? J Nucl Cardiol 2012;19:1026-43.

2. Iskandrian AE, Garcia EV. Nuclear cardiac imaging: Principles and applications. Oxford: Oxford University Press; 2015 (In press). 
3. Iskandrian AE, Hage FG, Shaw LJ, Mahmarian JJ, Berman DS. Serial myocardial perfusion imaging: Defining a significant change and targeting management decisions. JACC Cardiovasc Imaging 2014;7:79-96.

4. El-Hajj S, AlJaroudi WA, Farag A, Bleich S, Manaoragada P, Iskandrian $\mathrm{AE}$ et al. Effect of changes in perfusion defect size during serial regadenoson myocardial perfusion imaging on cardiovascular outcomes in high-risk patients. J Nucl Cardiol 2015.

5. Slomka PJ, Nishina H, Berman DS, Kang X, Friedman JD, Hayes SW, et al. Automatic quantification of myocardial perfusion stressrest change: A new measure of ischemia. J Nucl Med 2004;45:183-91.

6. Slomka PJ, Berman DS, Germano G. Quantification of serial changes in myocardial perfusion. J Nucl Med 2004;45:1978-80.

7. Germano G, Kavanagh PB, Slomka PJ, Berman DS. Tracking a therapeutic response: How reliable are serial measurements of LV perfusion and function? J Nucl Cardiol 2012;19:360-3.

8. Faber TL, Modersitzki J, Folks RD, Garcia EV. Detecting changes in serial myocardial perfusion SPECT: A simulation study. J Nucl Cardiol 2005;12:302-10.

9. deKemp RA, Ruddy TD, Hewitt T, Dalipaj MM, Beanlands RS. Detection of serial changes in absolute myocardial perfusion with 82Rb PET. J Nucl Med 2000;41:1426-35.

10. Mahmarian JJ, Peterson LE, Xu J, Cerqueira MD, Iskandrian AE, Bateman TM, et al. Regadenoson provides perfusion results comparable to adenosine in heterogeneous patient populations: A quantitative analysis from the ADVANCE MPI trials. J Nucl Cardiol 2015;22:248-61.

11. Shaw LJ, Berman DS, Picard MH, Friedrich MG, Kwong RY, Stone GW, et al. Comparative definitions for moderate-severe ischemia in stress nuclear, echocardiography, and magnetic resonance imaging. JACC Cardiovasc Imaging 2014;7:593-604.

12. Iskandrian AE. Myocardial perfusion imaging: Lessons learned and work to be done. By the Editorial Team of the Journal. J Nucl Cardiol 2014;21:4-16.

13. Shaw LJ, Hendel R, Borges-Neto S, Lauer MS, Alazraki N, Burnette J, et al. Prognostic value of normal exercise and adenosine (99m)Tc-tetrofosmin SPECT imaging: Results from the multicenter registry of 4,728 patients. J Nucl Med 2003;44:134-9.

14. Zellweger MJ, Hachamovitch R, Kang X, Hayes SW, Friedman JD, Germano G, et al. Threshold, incidence, and predictors of prognostically high-risk silent ischemia in asymptomatic patients without prior diagnosis of coronary artery disease. J Nucl Cardiol 2009;16:193-200.
15. Fihn SD, Gardin JM, Abrams J, Berra K, Blankenship JC, Dallas AP, et al. 2012 ACCF/AHA/ACP/AATS/PCNA/SCAI/STS Guideline for the diagnosis and management of patients with stable ischemic heart disease: A report of the American College of Cardiology Foundation/American Heart Association Task Force on Practice Guidelines, and the American College of Physicians, American Association for Thoracic Surgery, Preventive Cardiovascular Nurses Association, Society for Cardiovascular Angiography and Interventions, and Society of Thoracic Surgeons. J Am Coll Cardiol 2012;60:e44-164.

16. Zellweger MJ, Maraun M, Osterhues HH, Keller U, Muller-Brand $\mathrm{J}$, Jeger R, et al. Progression to overt or silent CAD in asymptomatic patients with diabetes mellitus at high coronary risk: Main findings of the prospective multicenter BARDOT trial with a pilot randomized treatment substudy. JACC Cardiovasc Imaging 2014;7:1001-10.

17. Young LH, Wackers FJ, Chyun DA, Davey JA, Barrett EJ, Taillefer R, et al. Cardiac outcomes after screening for asymptomatic coronary artery disease in patients with type 2 diabetes: The DIAD study-a randomized controlled trial. JAMA 2009;301:1547-55.

18. Shaw LJ, Cerqueira MD, Brooks MM, Althouse AD, Sansing VV, Beller GA, et al. Impact of left ventricular function and the extent of ischemia and scar by stress myocardial perfusion imaging on prognosis and therapeutic risk reduction in diabetic patients with coronary artery disease: Results from the Bypass Angioplasty Revascularization Investigation 2 Diabetes (BARI 2D) trial. J Nucl Cardiol 2012;19:658-69.

19. Shaw LJ, Berman DS, Maron DJ, Mancini GB, Hayes SW, Hartigan PM, et al. Optimal medical therapy with or without percutaneous coronary intervention to reduce ischemic burden: Results from the Clinical Outcomes Utilizing Revascularization and Aggressive Drug Evaluation (COURAGE) trial nuclear substudy. Circulation 2008;117:1283-91.

20. Mahmarian JJ, Cerqueira MD, Iskandrian AE, Bateman TM, Thomas GS, Hendel RC, et al. Regadenoson induces comparable left ventricular perfusion defects as adenosine: A quantitative analysis from the ADVANCE MPI 2 trial. JACC Cardiovasc Imaging 2009;2:959-68.

21. Ather S, Iqbal F, Gulotta J, Aljaroudi W, Heo J, Iskandrian AE, et al. Comparison of three commercially available softwares for measuring left ventricular perfusion and function by gated SPECT myocardial perfusion imaging. J Nucl Cardiol 2014;21:673-81. 